DOI: $10.5277 /$ epe 160401

\author{
ELŻBIETA MALINOWSKA ${ }^{1}$
}

\title{
ZINC SPECIATION IN SOIL UNDER VARIOUS RATES OF SEWAGE SLUDGE AND LIMING
}

\begin{abstract}
The influence of sewage sludge doses and liming on the speciation of zinc in the soil has been investigated. For the highest dose of sludge, $15 \mathrm{wt}$. \%, more than twofold increase in zinc content compared with the control has been observed. Based on sequential analysis of zinc content in sewage sludge, it was found that its concentration in the easily soluble and exchangeable fractions was low while it was the highest in the organic fraction. The concentration of zinc in selected soil fractions was dependent on the sludge dose and liming. In the first year of the experiment, zinc was mainly bound to organic matter and residual, while in the second year - to organic matter. In limed soil, much more zinc was bound to the residual fraction compared with the soil without liming.
\end{abstract}

\section{INTRODUCTION}

Agricultural utilisation of sludge and its use in soil rehabilitation are highly feasible economically due to the possibility of taking advantage of substantial amounts of organic matter and biogenic components present in this kind of waste [1,2]. Agricultural usage of sludge is strictly limited due to overrepresentation of toxic substances, i.e. heavy metals and sanitary contamination [3]. In soil, particularly acidic, heavy metals undergo processes changing their concentrations and chemical formulas. $\mathrm{pH}$ of soil is the decisive factor influencing the strength of bonds of heavy metals to an organic substance. Liming changes soil chemical and physical properties, maintaining a favourable structure and the optimal air-to-water ratio as well as reducing the content and uptake of heavy metals in plants. Zinc is thought to be the most mobile element in soil and its desorption decreases upon increasing $\mathrm{pH}$. Its mobility depends on the redox potential, organic matter content, granulometric composition, and calcium and magnesium saturation of the soil adsorption complex [4]. Aluminum, iron and clay minerals bind zinc

${ }^{1}$ Department of Grassland and Green Areas Creation, Institute of Agronomy, Siedlce University of Natural Sciences and Humanities, Poland, e-mail: malinowskae@uph.edu.pl 
but in the process of weathering all zinc compounds are soluble, in particular in an acid environment, and the ions released form mineral and organic-mineral bonds of high mobility $[5,6]$.

The overall content of metals is not always a good indicator of their bio-assimilability $[7,8]$. The speciation analysis allows specifying mobility of elements or possibility of their passing to the soil solution, and thus to the biogeochemical circulation. The widely used methods of sequential extraction of elements, including heavy metals, from soil is based on isolating or extracting a metal bound to other soil components by adding various extractant solutions. These methods make it possible to determine the concentration of heavy metals in soil and, at the same time, to assess their availability and toxicity to components of biotic factors at trophic levels [9]. Sequential extraction is more sensitive than single extraction because the order of sequences can be used to trace metal demobilization as an effect of the change in environmental conditions [10]. This technique is more and more commonly used and recommended for testing soils contaminated with heavy metals and for testing waste containing elevated content of these elements [11-13].

The aim of the study, done as an incubation experiment, was to evaluate the impact of applying various doses of sewage sludge and liming on the zinc speciation in soil.

\section{MATERIALS AND METHODS}

The incubation experiment was conducted over the period of two years in laboratory conditions and replicated three times. Containers were filled with $3 \mathrm{~kg}$ of soil (topsoil level) of the $\mathrm{pH}=4.29$, and with the granulometric content resembling loamy sand, according to the Polish Society of Soil Science [14]. The overall concentration of heavy metals in soil before the experiment was lower than that recommended in the Regulation of the Minister of the Environment concerning the use of municipal sludge on light soil [15], being equal to $\left(\mathrm{mg} \cdot \mathrm{kg}^{-1}\right): \mathrm{Pb}-6.0, \mathrm{Cd}-0.12, \mathrm{Cr}-2.1, \mathrm{Cu}-2.2, \mathrm{Zn}-19.9, \mathrm{Ni}-1.6$.

The soil, before filling the containers, was sieved through a sieve of a one-centimetre mesh and divided into two parts, with one part limed with $\mathrm{CaCO}_{3}$, equivalent to hydrolytic acidity $\mathrm{Hh}=1$, and left for a period of one month to bring it to the humidity of $50-60 \%$, the maximum water capacity. Then 5,10 and 15 wt. \% of fresh sludge originating from the municipal mechanical-biological sewage sludge plant in Siedlce was added, and the components were thoroughly mixed. The heavy metal content in the sewage sludge was $\left(\mathrm{mg} \cdot \mathrm{kg}^{-1}\right): \mathrm{Pb}-50.2, \mathrm{Cd}-0.17, \mathrm{Cr}-19.9, \mathrm{Cu}-85.0, \mathrm{Zn}-1120$, $\mathrm{Ni}-50.1$. Nitrogen concentration was $40 \mathrm{~g} \cdot \mathrm{kg}^{-1}$, with the dry matter content of $25 \%$. Heavy metals concentration in the sludge tested did not exceed limits recommended in the Regulation of the Minister of the Environment on agricultural utilization of sewage sludge [16]. Two controls were established in the experiment: one without the sludge and without $\mathrm{CaCO}_{3}$, and the other without the sludge but with the addition of $\mathrm{CaCO}_{3}$. 
During the experiment, the soil humidity was kept at $50-60 \%$ of the maximum water capacity and temperature at $20-22^{\circ} \mathrm{C}$. Soil samples were collected four times in 30-day intervals (first year of the experiment). In the second year, the soil was sampled twice in 60-day intervals. In all soil samples, total zinc concentration was established after dry mineralisation at $450{ }^{\circ} \mathrm{C}$ by the atomic absorption spectroscopy method. Carbon concentration in organic compounds was determined by the oxidation-titration method and the zinc fractions by the 7-degree Zeien and Brümmer method [9] (Table1).

Table 1

Sequential extraction of heavy metals by the Zeien and Brümmer method [9] ${ }^{\mathrm{a}}$

\begin{tabular}{|c|l|l|c|c|}
\hline Fraction & \multicolumn{1}{|c|}{ Feature } & \multicolumn{1}{|c|}{ Extraction reagent } & $\begin{array}{c}\text { Extraction } \\
\text { time } \\
{[\mathrm{h}]}\end{array}$ & $\mathrm{pH}$ \\
\hline $\mathrm{F} 1$ & easily soluble & $1 \mathrm{M} \mathrm{NH}_{4} \mathrm{NO}_{3}$ & 24 & natural \\
\hline $\mathrm{F} 2$ & exchangeable & $1 \mathrm{M} \mathrm{CH}_{3} \mathrm{COONH}_{4}$ & 24 & 6.0 \\
\hline $\mathrm{F} 3$ & bound to $\mathrm{MnO}_{x}$ & $1 \mathrm{M} \mathrm{NH}_{2} \mathrm{OH} \cdot \mathrm{HCl}+1 \mathrm{M} \mathrm{CH}_{3} \mathrm{COONH}_{4}$ & 0.5 & 6.0 \\
\hline F4 & $\begin{array}{l}\text { Forg bound to } \\
\text { organic matter }\end{array}$ & $0.025 \mathrm{M} \mathrm{C}_{10} \mathrm{H}_{22} \mathrm{~N}_{4} \mathrm{O}_{8}$ & 1.5 & 4.6 \\
\hline F5 & $\begin{array}{l}\text { bound to } \\
\text { amorphous } \mathrm{FeO}_{x}\end{array}$ & $0.2 \mathrm{M}\left(\mathrm{NH}_{4}\right)_{2} \mathrm{C}_{2} \mathrm{O}_{4}+0.2 \mathrm{M} \mathrm{H}_{2} \mathrm{C}_{2} \mathrm{O}_{4} \cdot \mathrm{dm}^{-3}$ & 4 & 3.25 \\
\hline F6 & $\begin{array}{l}\text { bound to } \\
\text { crystalline } \mathrm{FeO}\end{array}$ & $\begin{array}{l}0.2 \mathrm{M}\left(\mathrm{NH}_{4}\right)_{2} \mathrm{C}_{2} \mathrm{O}_{4}+0.2 \mathrm{M} \mathrm{H}_{2} \mathrm{C}_{2} \mathrm{O}_{4} \\
+0.1 \mathrm{M} \mathrm{C}_{6} \mathrm{H}_{8} \mathrm{O}_{6}\end{array}$ & 0.5 & 3.25 \\
\hline F7 & Fresid residual & $\begin{array}{l}\text { calculated as the difference between the total content } \\
\text { of zinc and the sum of the above determined fractions }\end{array}$ & & - \\
\hline
\end{tabular}

aProportion of soil to solution: $1 \mathrm{~g} / 10 \mathrm{~cm}^{3}$.

The zinc and carbon concentrations were processed statistically to analyse means with the analysis of variance (using the Statystica software, Version 10.0 StatSoft). Tukey's test was used to calculate the $\mathrm{LSD}_{0.05}$ value. The straight correlation coefficients between carbon content and zinc fractions in the soil were calculated.

\section{RESULTS AND DISCUSSION}

In the two-year incubation experiment, substantial differences were found in the concentration of zinc in the sludge fertilised soil (Table 2). Over the course of the entire experiment, with the highest dose of sludge in the soil (15 wt. \%), the concentration of the tested metal at all dates was more than twofold higher than in the control. In all measurement periods, the concentration of zinc was much lower than the maximum concentration allowed for agricultural land [16] which in the top part of light soil should not exceed $150 \mathrm{mg} \cdot \mathrm{kg}^{-1}$ of soil dry matter [16] 
Table 2

Total content of zinc $\left[\mathrm{mg} \cdot \mathrm{kg}^{-1}\right]$ in soil in the incubation experiment

\begin{tabular}{|c|c|c|c|c|c|c|c|c|c|c|}
\hline \multirow{3}{*}{ Days } & Control object & $5 \%$ & $10 \%$ & $15 \%$ & Mean & Control object & $5 \%$ & $10 \%$ & $15 \%$ & Mean \\
\cline { 2 - 11 } & \multicolumn{10}{|c|}{ After liming } \\
\cline { 2 - 12 } & \multicolumn{10}{|c|}{ First year of experiment } \\
\hline 30 & 19.8 & 41.9 & 45.2 & 58.0 & 41.2 & 23.1 & 45.6 & 42.7 & 57.6 & 42.2 \\
\hline 60 & 21.7 & 37.2 & 45.6 & 63.8 & 42.1 & 20.8 & 39.9 & 46.9 & 57.5 & 41.3 \\
\hline 90 & 19.9 & 32.1 & 70.8 & 63.7 & 46.6 & 22.7 & 56.0 & 47.3 & 51.2 & 44.3 \\
\hline 120 & 32.7 & 38.5 & 55.9 & 66.4 & 48.4 & 22.3 & 43.7 & 53.2 & 62.6 & 45.4 \\
\hline mean & 21.5 & 37.4 & 54.4 & 60.5 & 43.9 & 21.3 & 46.3 & 47.5 & 57.2 & 43.3 \\
\hline
\end{tabular}

LSD $_{0.05}$ for: $A=2.38, B=$ n.s., $C=2.38$,

$A / B=3.36, B / A=2.55, A / C=3.36, C / A=3.36, B / C=$ n.s. $C / B=$ n.s.

\begin{tabular}{|c|c|c|c|c|c|c|c|c|c|c|}
\hline \multicolumn{10}{|c|}{ Second year of experiment } \\
\hline 60 & 16.7 & 34.7 & 40.4 & 63.5 & 38.8 & 16.5 & 32.1 & 41.1 & 49.0 & 34.7 \\
\hline 120 & 15.4 & 30.7 & 48.2 & 55.8 & 37.5 & 21.5 & 30.9 & 44.2 & 50.5 & 36.8 \\
\hline mean & 16.0 & 32.7 & 44.4 & 59.6 & 38.2 & 18.9 & 31.5 & 42.6 & 49.8 & 35.7 \\
\hline
\end{tabular}

$\mathrm{LSD}_{0.05}$ for: $A=1.14, B=0.61, C=$ n.s.

$A / B=1.61, B / A=1.21, A / C=1.61, C / A=1.21, B / C=0.86, C / B=0.86$.

n.s. - not significant, 5 wt. $\%, 10$ wt. $\%, 15$ wt. $\%$ of sewage sludge to dry mass of soil.

$A$ - fertilization, $B$ - liming, $C$-days, $A / B, B / A, A / C, C / A, B / C, C / B$-interaction.

Table 3

The content of carbon $\left[\mathrm{g} \cdot \mathrm{kg}^{-1}\right]$ in soil in the incubation experiment

\begin{tabular}{|c|c|c|c|c|c|c|c|c|c|c|}
\hline \multirow{3}{*}{ Days } & Control object & $5 \%$ & $10 \%$ & $15 \%$ & Mean & Control object & $5 \%$ & $10 \%$ & $15 \%$ & Mean \\
\hline & \multicolumn{5}{|c|}{ Without liming } & \multicolumn{5}{|c|}{ After liming } \\
\hline & \multicolumn{10}{|c|}{ First year of experiment } \\
\hline 30 & 10.1 & 10.9 & 12.4 & 13.8 & 11.8 & 10.3 & 11.0 & 13.1 & 14.0 & 12.1 \\
\hline 60 & 10.0 & 11.2 & 12.9 & 13.9 & 12.0 & 10.2 & 12.2 & 13.5 & 15.0 & 12.7 \\
\hline 90 & 10.0 & 12.8 & 13.9 & 14.8 & 12.9 & 10.5 & 12.6 & 14.1 & 15.1 & 13.1 \\
\hline 120 & 10.9 & 12.6 & 14.3 & 14.5 & 13.1 & 10.6 & 13.5 & 13.6 & 14.5 & 13.1 \\
\hline mean & 10.3 & 11.9 & 13.4 & 14.3 & 12.4 & 10.4 & 12.3 & 13.6 & 14.7 & 12.7 \\
\hline \multicolumn{11}{|c|}{$\begin{array}{l}\text { LSD }_{0.05} \text { for: } A=0.49, B=0.27, C=0.49 \\
A / B-\text { n.s., } B / A-\text { n.s., } A / C=0.70, C / A=0.70, B / C, C / B-\text { n.s. }\end{array}$} \\
\hline \multicolumn{11}{|c|}{ Second year of experiment } \\
\hline 60 & 10.5 & 12.3 & 13.8 & 15.0 & 12.9 & 10.6 & 12.8 & 14.0 & 15.2 & 13.1 \\
\hline 120 & 10.8 & 12.4 & 13.9 & 14.8 & 13.0 & 10.8 & 12.7 & 14.1 & 15.0 & 13.2 \\
\hline mean & 10.7 & 12.4 & 13.9 & 14.9 & 12.9 & 10.7 & 12.8 & 14.1 & 15.1 & 13.2 \\
\hline & ation, $B$ & $\mathrm{~s}$ & 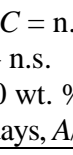 & & 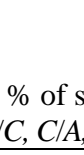 & $C D$ & & ii & & \\
\hline
\end{tabular}


In the first year of the experiment, the liming of the soil did not have any substantial impact on the total zinc concentration. In the second year, substantial differences were found in the $\mathrm{Zn}$ content in the limed soil with doses of sludge added.

During the experiment, the application of sewage sludge caused an increase in carbon concentration in soil organic compounds compared to the control object (Table 3).

A key role of sludge in restoring the stock of organic matter in soils is confirmed by the research of Maćkowiak [17]. The doses of sludge and liming made a substantial difference in the content of organic carbon. In the second year of the experiment, an increased concentration of organic carbon was reported after the application of higher doses of sludge, on average $14.9 \mathrm{~g} \cdot \mathrm{kg}^{-1}$ in non-limed soil and $15.1 \mathrm{~g} \cdot \mathrm{kg}^{-1}$ in limed soil. In the soil of the controls, carbon content was slightly over $10 \mathrm{~g} \cdot \mathrm{kg}^{-1}$.

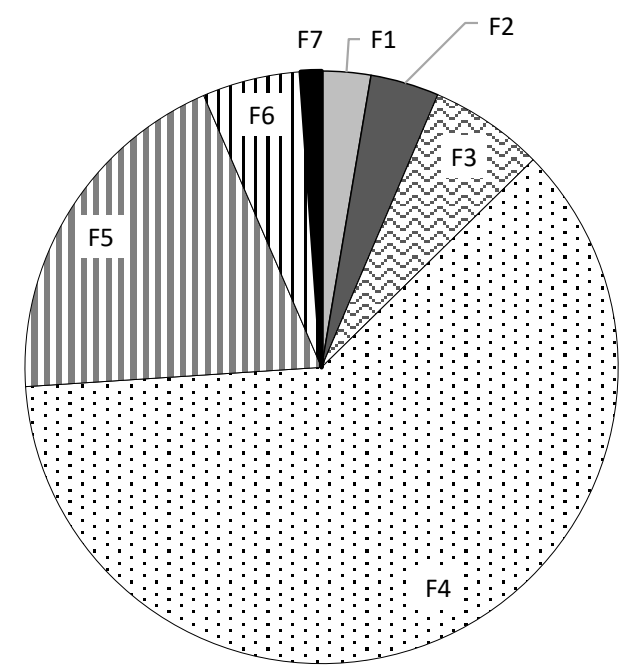

Fig. 1. Percentage share of zinc fractions in its total content in sewage sludge:

$\mathrm{F} 1$ - easily soluble, $\mathrm{F} 2$ - exchangeable, $\mathrm{F} 3$ - bound to $\mathrm{MnO}_{x}$,

$\mathrm{F} 4$ - bound to organic matter, $\mathrm{F} 5$ - bound to amorphous $\mathrm{FeO}_{x}$, $\mathrm{F} 6$ - bound to crystalline $\mathrm{FeO}_{x}, \mathrm{~F} 7$ - residual

Sequential analysis of zinc in the sludge, determined by the Zeien and Brümmer method [9] showed the highest content of Zn (61.3\%) in the organic fraction F4 (Fig. 1). The dominance of this fraction is typical of most kinds of sludge [18]. On the other hand, zinc in the tested sludge was found to be only slightly bio-accessible. The total of F1 and F2 fractions amounted to $6.41 \%$. The similarly low amount of absorbable zinc in plants growing on soil with sludge was reported by Shrivastava and Banerjee [19]. Zinc bound to $\mathrm{MnO}_{x}(\mathrm{~F} 3)$ made up 6.23\%, bound to amorphous $\mathrm{FeO}_{x}(\mathrm{~F} 5) 19.53 \%$, bound to crystalline $\mathrm{FeO}_{x}$ (F6) 5.38\%. The lowest content of $\mathrm{Zn}$ was reported in the residual fraction $\left(\mathrm{F}_{\text {resid }}\right.$ residual $\left.-\mathrm{F} 7\right)$, slightly over $1 \%$. 
Sequential analysis of zinc concentration in soil proved a great differentiation in its content depending on the dose of the sludge and liming (Figs. 2--7). The difference in the mobility of zinc in soil fertilised with sludge is confirmed by the research of Hlavay et al. [20] and Patorczyk-Pytlik [21].

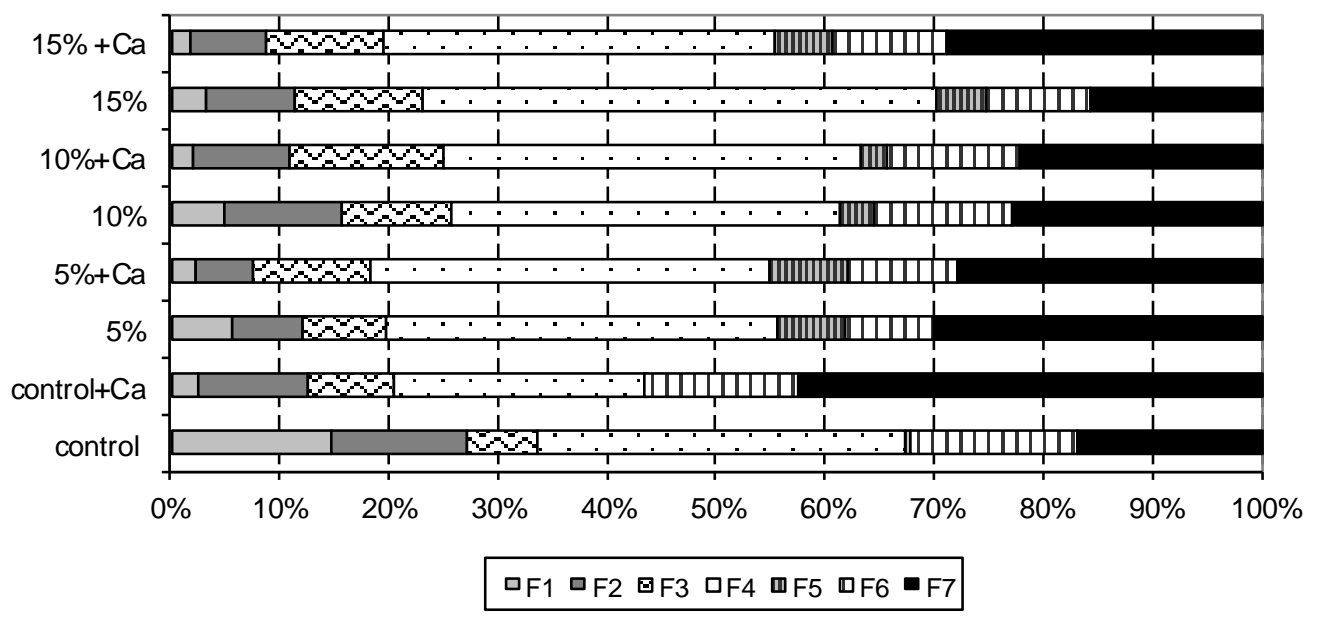

Fig. 2. Percentage share of zinc fractions in its total content in the soil after 30 days

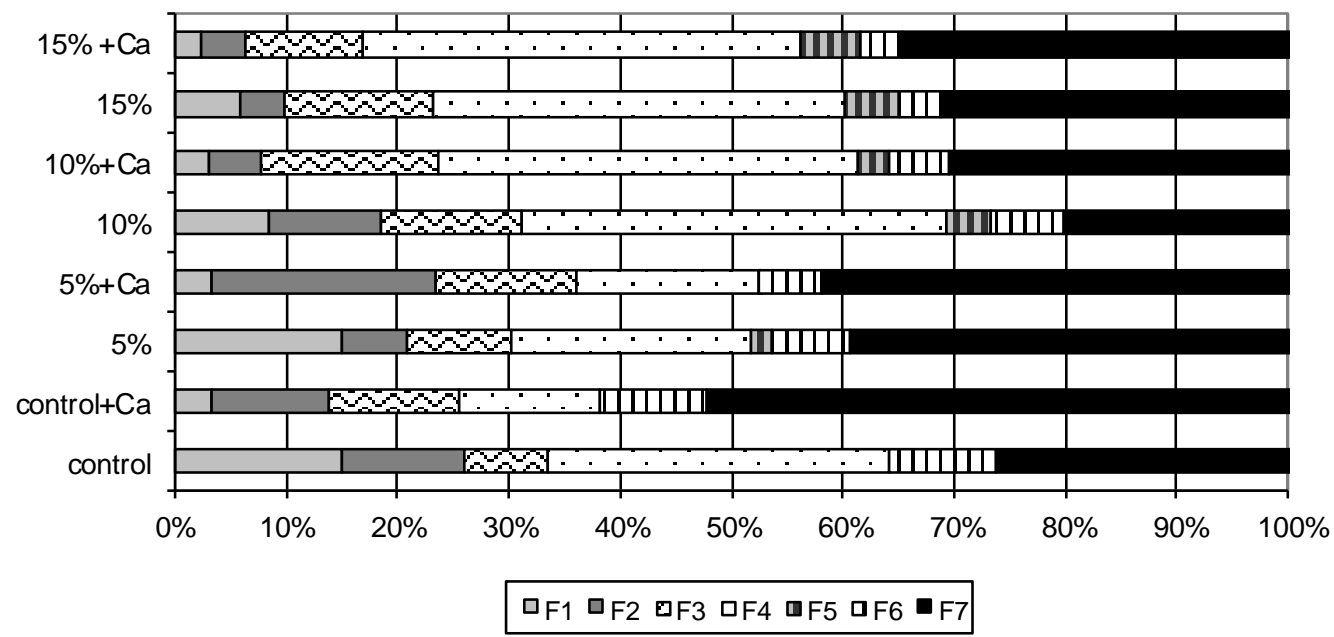

Fig. 3. Percentage share of zinc fractions in its total content in the soil after 60 days

The greatest share of mobile zinc forms was observed in non-limed soil in the control. The total content of easily soluble (F1) and exchangeable (F2) fractions is normally over $20 \%$, while in the control with $\mathrm{CaCO}_{3}$, the total content of these fractions does not 
exceed $15 \%$, except for the second year of the experiment. Compared to other doses, the lowest dose of sludge ( $5 \mathrm{wt} . \%$ ) caused the highest mobility of zinc in the soil. The percentage share of zinc in the soluble fraction was more than twofold higher in the nonlimed soil and constituted more than $10 \%$ of its total content in the soil, except for the first test period.

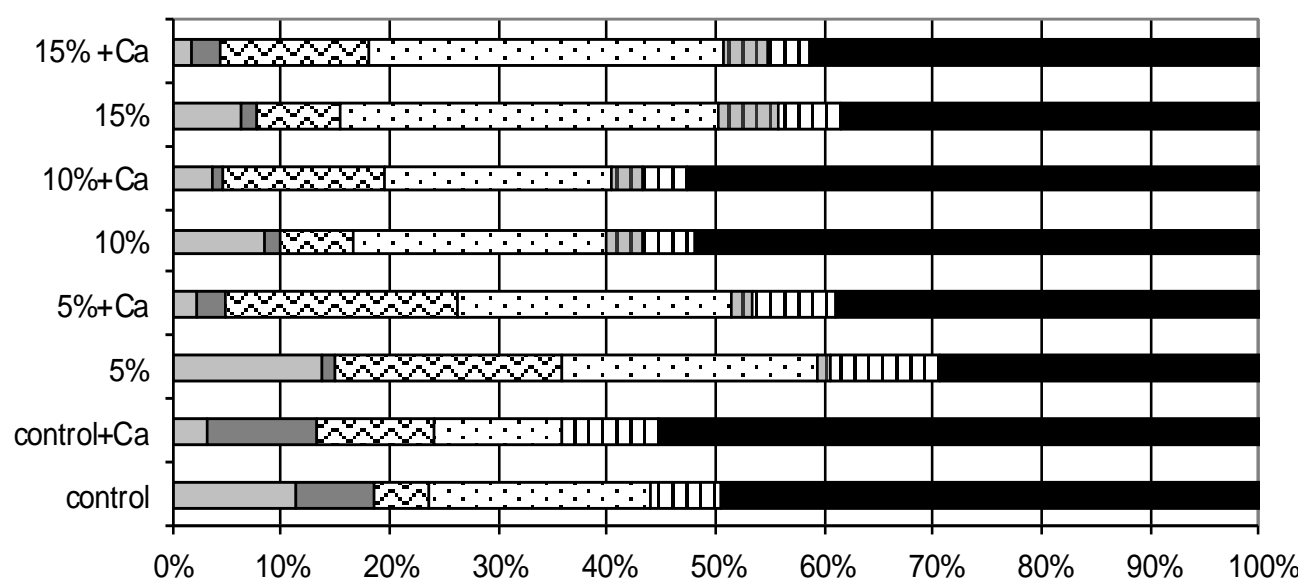

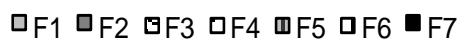

Fig. 4. Percentage share of zinc fractions in total content in the soil after 90 days

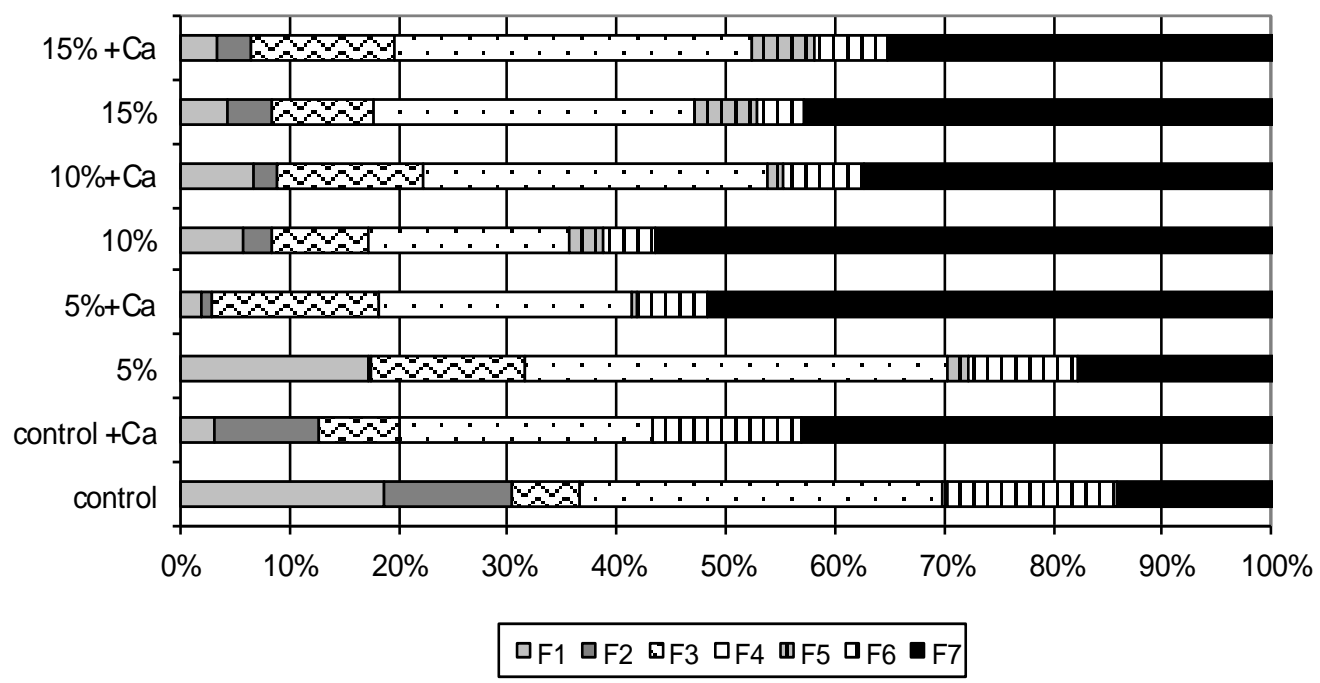

Fig. 5. Percentage share of zinc fractions in total content in the soil after 120 days 


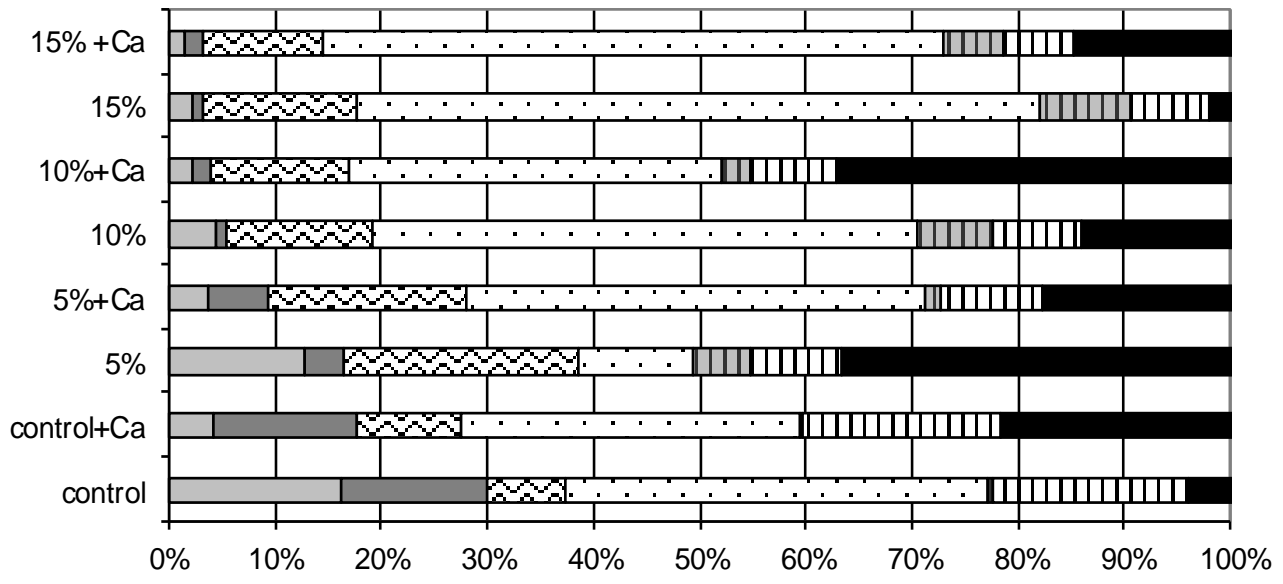

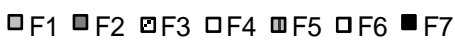

Fig. 6. Percentage share of zinc fractions in total content in the soil after 60 days in the second year

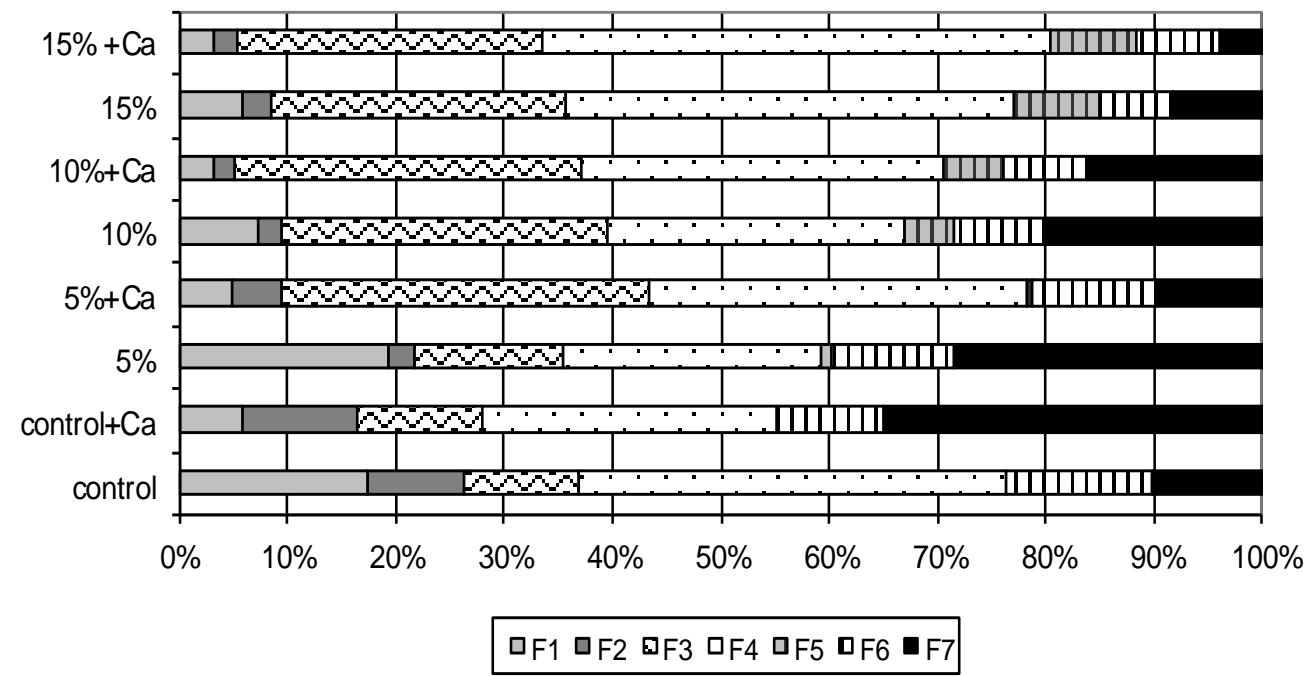

Fig. 7. Percentage share of zinc fractions in total content in the soil after 120 days in the second year

Much higher amounts of absorbable zinc in soil fertilised with compost from sludge have been reported by Patorczyk-Pytlik [21]. In the soil with the addition of sludge, a greater share of zinc bound to $\mathrm{MnO}_{x}(\mathrm{~F} 3)$ was recorded as compared to the soil in the control. The amount of this fraction increased in proportion to the progressive mineralization of sludge and in the second year of the experiment ranged from 10 to $35 \%$. The greatest share of the total zinc pool in soil was the metal-organic $\left(\mathrm{F}_{\text {org }}\right.$ bound to organic 
matter - F4) and residual fractions $\left(\mathrm{F}_{\text {resid }}\right.$ residual - F7), mainly in the first year. The mineralization of sludge triggered the occurrence of this element in the soil due to significant reduction in the amount of zinc in the post-extraction residues (F7). After the application of sludge, the share of zinc in the residual fraction was even above $50 \%$ in non-limed soil. In the second year of the experiment (Fig. 7) in non-limed soil the content of zinc in this fraction was up to $28 \%$, while in limed objects it was up to $35 \%$ of its total content in the soil. The dominating role of extremely durable organic and mineral compounds of zinc in soil was established by Kalembasa and Pakuła [22, 23]. Zinc was also present in large amounts in compounds with iron oxides, particularly crystalline ones, with the total of F5 and F6 slightly over 10\%. McBride [24] reports that zinc is strongly bound with iron and manganese oxides.

The control systems of environmental pollution should primarily include the first link in the food chain, namely the soil. Usually, such assessment is only carried out basing on the total or close-to-total content of heavy metals in the soil. It is an imprecise assessment due to a significant variability of soil factors, which may substantially impact the bio-absorption of heavy metals. The recognition of mobility, i.e. the possibility of the elements to transfer into the soil solution and thus to the biogeochemical circulation, is necessary for the assessment of the condition of the environment [25].

Table 4

Simple correlation coefficients between carbon content and zinc fractions in the soil in the two-year experiment

\begin{tabular}{|c|c|c|c|c|}
\hline \multirow{2}{*}{ Fraction } & \multicolumn{2}{|c|}{ First year } & \multicolumn{2}{c|}{ Second year } \\
\cline { 2 - 5 } & Without liming & After liming & Without liming & After liming \\
\hline F1 & 0.084 & $0.595^{*}$ & -0.240 & 0.235 \\
\hline F2 & -0.085 & -0.155 & -0.598 & $-0.909^{*}$ \\
\hline F3 & $0.749^{*}$ & $0.794^{*}$ & $0.778^{*}$ & 0.633 \\
\hline F4 & $0.755^{*}$ & $0.817^{*}$ & $0.850^{*}$ & $0.927^{*}$ \\
\hline F5 & $0.784^{*}$ & $0.628^{*}$ & $0.889^{*}$ & $0.860^{*}$ \\
\hline F6 & 0.135 & 0.109 & $0.833^{*}$ & $0.746^{*}$ \\
\hline F7 & $0.698^{*}$ & $0.585^{*}$ & 0.527 & 0.173 \\
\hline
\end{tabular}

$p<0.05$, critical value $r=0.482$ for the first year, $r=0.666$ for the second year.

Based on the statistical analysis in non-limed soil, in the first and second years of the experiment, a significant positive relation was established between the content of carbon in organic compounds and the content of zinc in the fraction bound to $\mathrm{MnO}_{x}$ (F3). A similar relation was between carbon concentration and the organic fraction ( $\mathrm{F}_{\text {org }}$ bound to organic matter $-\mathrm{F} 4$ ) or zinc normally bound to amorphous $\mathrm{FeO}_{x}$ (F5). There was also a positive correlation between carbon content and the concentration of zinc in residues $\left(\mathrm{F}_{\text {resid }}\right.$ residual $\left.-\mathrm{F} 7\right)$ in the first year of the experiment (Table 4). The content of organic carbon in limed soil was significantly positively correlated with the 
content of Zn in fractions F1, F3, F4, F5 and F7. In the second year, in limed soil, a negative relation was found between the contents of the carbon and the appearance of zinc in the exchangeable fraction (F2), along with a positive correlation between fractions F4, F5 and F6.

\section{CONCLUSIONS}

In the incubation experiment testing, the effect of sewage sludge doses and soil liming substantial differences were established in the contents of zinc in the soil with sewage sludge applied. The highest dose of the sludge ( $15 \mathrm{wt} . \%)$ caused more than twofold increase in zinc, compared with the control.

- In the soil samples taken every 30 days in the first year and every 60 days in the second year of the experiment, a significant relation between doses of sewage sludge and a content of carbon in organic compounds was found. The highest carbon content was found in the second year of the experiment in limed soil with the highest dose of sludge. Sequential analysis of zinc in municipal sludge showed a low content of $\mathrm{Zn}$ in bio-accessible compounds, with the highest in the organic fraction.

- In isolated fractions of the soil from individual objects, the percentage share of zinc in its overall content was dependent on the dose of sludge and liming. In the first year what dominated was zinc $\mathrm{F}_{\text {org }}$ bound to organic matter and $\mathrm{F}_{\text {resid }}$ residual, and in the second year zinc $\mathrm{F}_{\text {org }}$ bound to organic matter. In limed soil, much more zinc was bound to the residual fraction compared to the soil without liming.

\section{REFERENCES}

[1] Singh R.P., AGRAWAL M., Effects of sewage sludge amendment on heavy metal accumulation and consequent responses of beta vulgaris plants, Chemosphere, 2007, 67, 2229.

[2] Kalembasa D., Malinowska E., Bioaccumulation of zinc under the influence of sewage sludge and liming and speciation in soil, Fresenius Environ. Bull., 2013, 22 (11a), 3359.

[3] Aydinalp C., Marinova S., Distribution and forms of heavy metals in some agricultural soils, Polish J. Environ. Stud., 2003, 12 (5), 629.

[4] Yoo M.S., James B.R., Zinc exchangeability as a function of pH in citric acid am soils, Soil Sci., 2003, $168(5), 356$.

[5] Terelak H., Pietruch C., Tujaka A., The presence of zinc in surface levels of Polish agricultural soils, Zesz. Probl. Post. Nauk Roln., 2000, 472, 645.

[6] DomańsKa J., Soluble forms of zinc in profiles of selected types of arable soils, J. Elem. 2009, 14,1, 55.

[7] Amir S., Hafidi M., Merlina G., Revel J.C., Sequential extraction of heavy metals during composting of sewage sludge, Chemosphere, 2004, 59, 801.

[8] CZECHOWSKA-KosACKA A., Influence of sewage sludge solidification on immobilization of heavy metals, Polish J. Environ. Stud., 2007, 16 (2A), 625.

[9] ZEIEN H., BRÜMmer G.W., Chemische Extraktion zur Bestimmung von Schwermetallbindungsformen in Böden, Mittelign. Dtsch. Bodenkundl. Gesellsch., 1989, 59 (1), 505. 
[10] BACON J.R., DAVIDSON C.M., Is there a future for sequential chemical extraction?, The Analyst. Section: Critical Review, 2008, 122, 25.

[11] Glyzes C., Tellier S., Astruc M., Fractionation studies of trace elements in contaminated soils and sediments. A review of sequential extraction procedures, Trends Anal. Chem., 2002, 21, 451.

[12] RaO C.R.M., SAHUQuillo A., LoPEZ SANCHES J.F., A review of the different methods applied in environmental geochemistry for single and sequential extraction of trace elements in soils and related materials, Water Air Soil Poll., 2008, 189, 291.

[13] Yang Z., Ying W., Zhenyao S., Junfeng N., Zhenwn T., Distribution and speciation of heavy metals in sediments from the mainstream, tributaries, and lakes of the Yangtze River catchment of Wuhan, China J. Hazard. Mater., 2009, 166, 1186.

[14] Classification of soil particle size and mineral track - PTG, 2009, Roczn. Glebozn., 200960 (2), 5.

[15] Regulations of the Minister for Environment on soil quality standards and quality standards land, Dz.U. Nr 165, poz. 1359, 2002.

[16] Regulations of the Minister for Environment in question sewage sludge, Dz.U. Nr 137, poz. 924, 2010.

[17] Mас́кошіAK C., Chemical composition of sewage sludge and waste food industry about the importance of fertilizer, Nawozy i Nawożenie, 2000, 3 (4), 131 (in Polish).

[18] Attenbrough G.M., Smith S.R., Minski M.J., The fate and environmental activity of heavy metals in sewage sludge applied to soil, Proc. Int. Conf. Heavy Metals in the Environment, Hamburg, 1995, 2, 459.

[19] Shrivastava S.K., BANerJeE D.K., Speciation of metals in sewage sludge and sludge - amended soils, Water, Air, Soil Poll., 2004, 152, 219.

[20] Hlavay J., Prohaska T., Weisz M., Wenzel W.W., Stingeder G., Determination of trace elements bound to soils and sediment fractions, Pure Appl. Chem. 2004, 76 (2), 415.

[21] PATORCZYK-PytLiK B., Usefulness of the BCR procedure for assessing the mobility of Zn in sewage sludge composted by different methods. Part II. The content of $\mathrm{Zn}$ in maize depending on chemical form of this metal in sols fertilized with composted sewage sludges, Zesz. Probl. Post. Nauk Roln., 2006, 512, 457 (in Polish).

[22] Kalembasa D., Pakula K., Fractions of zinc and copper in the forest luvisols of the south Podlasie lowland, Polish J. Environ. Stud., 2006, 15 (2a), 98.

[23] Kalembasa D., PakuŁa K., Heavy metal fractions in soils fertilized with sewage sludge, Environ. Prot. Eng., 2009, 35 (2), 157.

[24] MCBRide M.B., Reactions controlling heavy metals solubility in soil, Adv. Soil Sci., 1989, 10, 1.

[25] Kalembiewicz J., Sočo E., Sequential extraction of metals from environmental samples, Chem. News, 2005, 59 (7-8), 700. 